\title{
Aligning PTCI Strategies to Global Corporate Strategies Using Scenario Planning
}

\author{
Welliam $^{1}$, Pri Hermawan ${ }^{2}$ \\ ${ }^{1,2}$ School of Business and Management, Institut Teknologi Bandung
}

\begin{abstract}
Profitability and growth are two important and essential measures to a firm existence and survivability. Profitability is critical to a company's short-term existence, and growth is crucial to long term survivability. Every business wants to maintain its existence and bring value to its stakeholders. Divestment and merger acquisition are part of the company strategy to achieve business growth that fulfil the company objectives, purpose, vision, and mission. In the case of a multinational company, it normally would have a global corporate strategy. Subsidiary companies will follow the strategic guidelines from its parent company. Thus, subsidiary company needs to align its strategy to the parent global corporate strategy.

Scenario planning used to answer the key focal issue about how to align subsidiary company strategy to its parent company global corporate strategy. One option for a firm to cope with uncertainty is scenario planning. Scenario planning is a unique tool compared to other decision analysis methodology. Scenario planning uses information on key uncertainties and certainties concerning the future to assemble an information rich illustration that provides eloquent descriptions of future worlds.

The data collected in this study comes from literature studies, interviews, questionnaires with internal and external stakeholders. External analysis is using the PESTEL framework and Porter Five Forces model. While internal analysis is using Growth-Share matrix, VRIO framework, and Strategic Diamond model. Information is consolidated to give driving forces that would shape up the future. Two driving forces that give the highest impact and uncertainty, Indonesia economic growth and company Product Innovation, are defined as critical uncertainty and used to construct a $2 \times 2$ scenario matrix. The scenario matrix, implication, options, and early warning systems are explored for each scenario to align subsidiary company strategy to its parent global company strategies.
\end{abstract}

KEYWORDS: Chemical Industry, Driving Forces, Global Strategy, Growth, Scenario Planning

\section{INTRODUCTION}

To become successful and survive in business or we can summarize as sustainable, both profitability and growth are important and essential for a firm to survive and remain attractive to investors and analysts. Profitability is, of course, critical to a company's existence, but growth is crucial to long-term survival. Profitability and growth work hand-in-hand to make a successful business. Profit is key to basic financial survival as a corporate entity, while growth is key to profit and long-term success. Growth makes organization easier to acquire assets, attract new talent and fund investments. It also drives business performance and profit to the uptrend. Nevertheless, businesses don't grow by themselves automatically. Many business firms started small and have become big through continuous growth. However, business growth is not a homogeneous process. The rate and pattern of growth varies from firm to firm. Some firms grow at a fast rate while others grow slowly. Some industries also grow faster than the others. Also, not all enterprises can survive to grow big. If a company is looking to achieve organic growth, it will need to put in place systems to drive the growth.

In 2021, PTCI parent company announced plans to focus on its core businesses and divest the business line which is PTCI's lines. PTCI parent company has decided not to divest PTCI assets for a strategic reason. To pursue growth then PTCI as a manufacturing site needs to have a business transformation that is in line with its parent strategy. As the situation escalated, scenario planning is used to explore questions that need to be answered for the next 5 years. How to achieve growth for PTCI? Where is the market that will sustain expected growth? What is the sector that will grow and degrow? Who are the customers and future customers?

This study objective is to explore relevant scenarios that are plausible for PTCI to pursue growth while aligning to the corporate global strategy. Scenario planning is an alternative way of dealing with uncertainty that is unique compared to other decision analysis 


\section{International Journal of Current Science Research and Review}

ISSN: 2581-8341

Volume 05 Issue 01 January 2022

DOI: 10.47191/ijcsrr/V5-i1-29, Impact Factor: 5.825

IJCSRR@ 2022

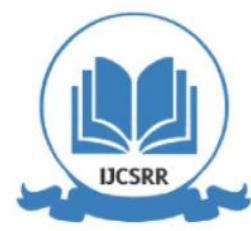

www.ijesrr.org

methodology. Scenarios planning focus on key uncertainties and certainties about the future and use this information to construct an information rich illustration that provides eloquent descriptions of future worlds. Scenario planning is a process that stimulates imaginative, creative thinking to better prepare an organization for the future. Scenario planning has been described as a way of rehearsing the future to avoid surprises by breaking through the "illusion of certainty".

\section{RESEARCH METHOD}

The data collected in this study comes from literature studies, interviews, questionnaires with internal and external stakeholders. All data collection from internal and external sources limited to PTCI and its parent company business line in specialty products for domestic and export markets within a 5-year time frame in Indonesia. All the processes are conducted online due to the restriction of pandemic and travelling.

\section{LITERATURE REVIEW}

\section{Conceptual Framework}

Scenario planning exercise proceeds through a complete five steps: orientation, exploration, scenario creation, identification of options and implications, and integration into current management processes. This study methodology is using scenario planning stages to generate scenarios for PTCI to provide orientation for PTCI Indonesia's manufacturing site to pursue growth and simultaneously aligning with its parent company strategies to focus on core businesses. Driving forces are defined through questionnaires and interviews with stakeholders using PESTEL model, Five Forces model, VRIO framework and Strategy Diamond model also literature study. The scenario creation process will result in four scenarios that are based on the two most critical uncertainties $2 \times 2$ matrix. Then the key characteristics of the scenarios identified, their cause-effect, and the events that may occur as the world evolved from the present to the destined future point. Options consideration involves the generation of implications and prioritization and selection of options using Growth-share matrix, VRIO framework, and Strategy Diamond model. Finally, is integration of scenarios into current management processes.

\section{Scenario Planning}

According to Börjeson et.al., there are three types of scenarios planning Predictive, Explorative, and Normative. These categories reflect three basically different modes of thinking about the future. Questions like How can a specific target be reached? are responded by Normative scenarios. Normative scenarios consist of two different types, distinguished by how the system structure is treated. Preserving scenarios respond to the question: How can the target be reached, by adjustments to the current situation? Transforming scenarios respond to the question: How can the target be reached, when the prevailing structure blocks necessary changes? (Börjeson, Höjer, Dreborg, Ekvall, \& Finnveden, 2006) This study is using a Normative-Predictive scenario planning model to answer how PTCI achieves expected growth while aligned within the global corporate strategy.

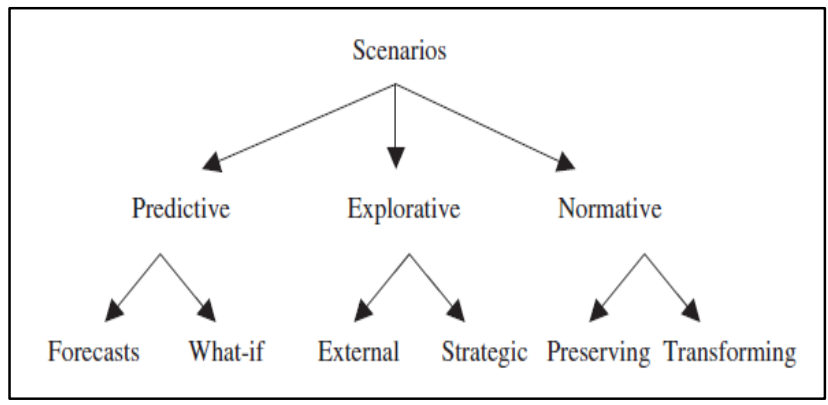

Figure 1. Type of scenarios (Börjeson et. Al., 2006)

\section{External Analysis}

PESTEL model is a framework or tool used by an organization to analyse and monitor the macro-environmental (external environment) factors that have an impact on an organization, company, or industry. PESTEL framework analysis on business issue for PTCI to pursue growth in Indonesia is summarized in Table $\mathbf{1 .}$ 


\section{International Journal of Current Science Research and Review}

ISSN: 2581-8341

Volume 05 Issue 01 January 2022

DOI: 10.47191/ijesrr/V5-i1-29, Impact Factor: 5.825

IJCSRR@ 2022

www.ijcsrr.org

Table 1. PESTEL Analysis Summary

\begin{tabular}{|l|l|}
\hline Factor & Impact \\
\hline Political & Political stability brings positive impact on pursuing growth in Indonesia. \\
\hline Economical & Interest rate and exchange rate are uncertainty factors on pursuing growth in Indonesia. \\
\hline Sociocultural & Middle income population is giving positive impact on pursuing growth in Indonesia. \\
\hline Technological & Market acceptance to specialty chemicals product become uncertainty on pursuing growth in Indonesia. \\
\hline Environment & $\begin{array}{l}\text { PTCI alignment to UN SDG ensuring environmental stewardship is a factor that needs to be complied } \\
\text { with in pursuing growth. }\end{array}$ \\
\hline Legal & High corruption index bring uncertainty on pursuing growth in Indonesia. \\
\hline
\end{tabular}

Defining the industry in which competition takes place is important for good industry analysis, not to mention for developing strategy and setting business unit boundaries. Defining the industry too broadly obscures differences among products, customers, or geographic regions that are important to competition, strategic positioning, and profitability. (Porter, 2008). PTCI is a specialty chemical company, and the core competency is its New Patented Product (NPP). Along with time, patents will expire and the NPP will become a commodity. Thus, it is not easy to enter the specialty chemical industry as an organization needs to have its own patent that needs time to develop or purchase a patent that will increase the cost through the royalty to the patent owner. As the patent expired and product becomes a commodity, the threat of an entrant is increasing but as a pioneer, PTCI will have advantage through economies of scale, network effects, and capital requirements. Thus, we can conclude that the threat of entrants is low.

Specialty chemicals products do not necessarily rely on cost efficiency and operational effectiveness. Thus, the cost structure of variable cost is less than $50 \%$ of the selling price. Supplier is not easy to increase the price or reduce the quality of the raw material as it can be substituted readily. i.e., Fatty acid as a raw material can be sourced from palm oil, sunflower oil, or rapeseed oil. But as the specialty chemical becomes a commodity, suppliers can differentiate their product to produce the commodity and become competitors that sell the same product with better positioning in variable cost. Nevertheless, it will take longer for suppliers to upgrade themselves to become a competitor of PTCI. As a result, we can also conclude that the threat of supplier is low.

Although specialty chemical prices are higher than commodities, it is providing a performance solution to the customer business. Thus, it is not easy to replace the product. For commodities, normally the threat of buyers is higher as commodities can be replaced more easily. But long-term relationship and better distribution channels help to retain the business. In summary, the threat of buyers is low.

Specialty chemical, unlike commodity chemicals, is tailored specifically as a solution to customer business. It will not be easy to replace but it is possible to substitute. Specialty chemicals need to evolve to answer problems in the customer business at a time. Once the specialty chemical is substituted it will be hard to claim back the market. Thus, the threat of substitutes is high and one factor of uncertainty on growing a business.

PTCI product portfolio ranged from commodity to premium specialty chemicals. Competition within commodity portfolio is fiercer than specialty chemical. PTCI is at the same position with its multinational company competitor in commodity business and ahead from local or regional competitors in terms of competencies. In the specialty chemicals market, PTCI positioned ahead due to its core competencies on new patented products (NPP). Nonetheless, every specialty chemical company has their own expertise and core competencies that make the competition tight.

\section{Internal Analysis}

An internal analysis scans an organization's internal environment to assess its resources, assets, characteristics, competencies, capabilities, and competitive advantages. In short, it lets us identify our organization's strengths and weaknesses, which can help management during the decision-making, strategy formulation, and execution processes.

The growth share matrix is a portfolio management framework that helps companies decide how to prioritize their different businesses. It is a table, split into four quadrants, each with its own unique symbol that represents a certain degree of profitability. This study utilizes the growth-share matrix to explore attractiveness of a sector, measuring internal strength of the sector, and 


\section{International Journal of Current Science Research and Review}

ISSN: 2581-8341

\section{Volume 05 Issue 01 January 2022}

DOI: 10.47191/ijcsrr/V5-i1-29, Impact Factor: 5.825

IJCSRR@ 2022

contribution of each sector to PTCI operation in Indonesia. This study uses sector revenue share and sector growth from 2016-2020 to product the growth-share matrix in Figure 2.

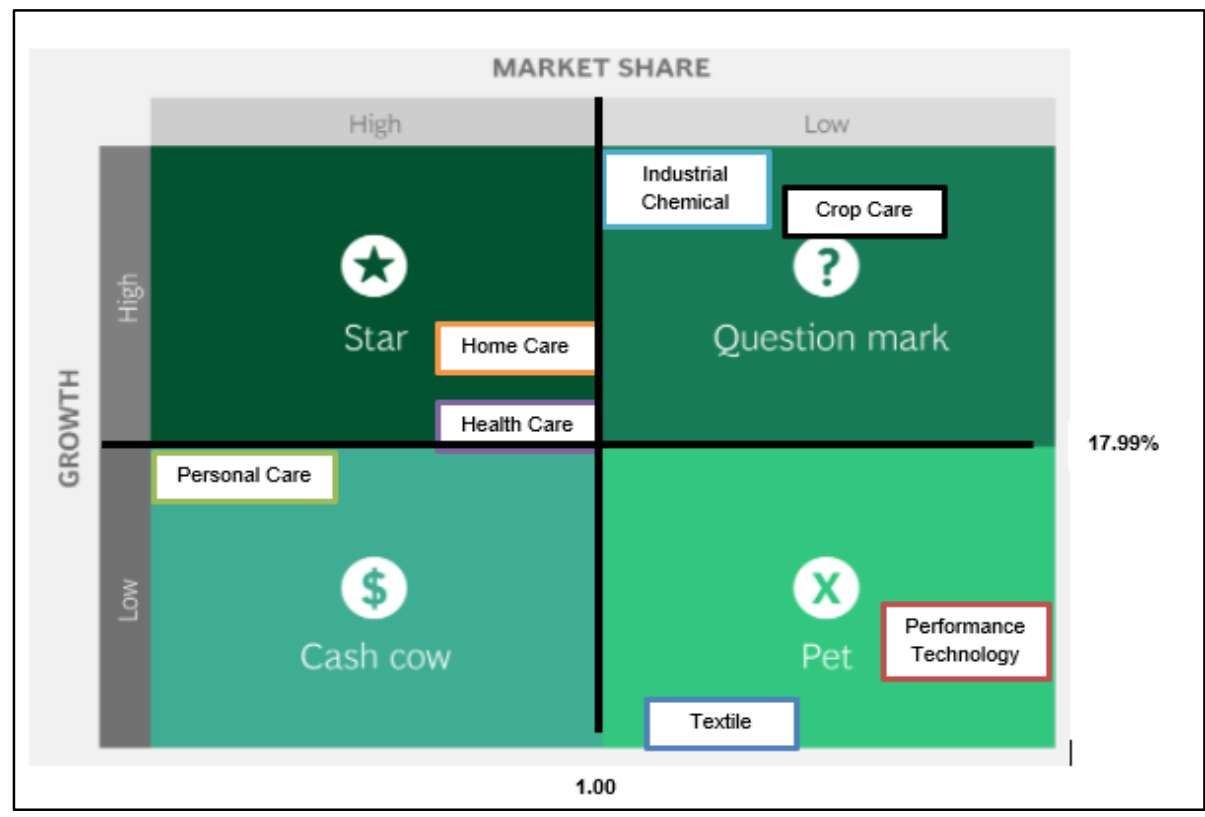

Figure 2. PTCI sectors growth-share matrix.

Industrial Chemical and Crop Care showed exponential growth with potential to become Stars but also possible to be downgraded to Pets. Industrial Chemical is a sector that could be downgraded to Pets as PTCI parent company strategy will exit the sector. PTCI sectors Home Care and Health Care sectors are the Stars as both are having high share and growth. PTCI parent company strategy also put both sectors as core business. PTCI Personal Care sector is considered as a mature business and have a good brand image. Thus, it generated the biggest revenue and profit that can be used to expand the Questions Mark and Stars to bring balance and stability in the portfolio and sectors that could bring additional growth to the PTCI operation in Indonesia while aligning to the global corporate strategy. PTCI Textile and Performance Technology sectors are the Pets. Even the Performance Technology portfolio will be divested by PTCI parent company. That will leave PTCI with a Textile business that needs to be revamped so it could be rejuvenated to become Question Mark and start a new life cycle.

Most companies possess various kinds of resources and capabilities. The VRIO framework is a strategy tool that helps organizations identify the resources and capabilities that give them a sustained competitive advantage. The VRIO analysis is an internal analysis that helps determine the quality and usefulness of a firm's resources and capabilities. Resources identified as PTCI sustainable competitive advantage are brand, new patented product, technical application expertise, and product transfer protocol.

Strategy is not primarily about planning. It is about intentional, informed, and integrated choices. A strategy consists of an integrated set of choices, but it isn't an all-encompassing for every important choice an executive face. Strategy is about making important choices, and the real strength of a Strategy Diamond is that it integrates important choices into a one big picture, instead of as a segregated approach. The five key parts of a strategy are: arenas, vehicles, differentiation, staging, and economic value. (Hambrick \& Fredrickson, 2005).

Arenas is the most fundamental choices that need to be defined are where, or in what arenas, the business will be active, or it can be simplified as "what business will we be in?" - Peter Drucker. To answer this question, we can extend further with answering below factors:

- Product category : New Patented Product, Specialty chemical, and Commodity chemical

- Market segment : Consumer Care, Life Science, and Textile

- Geographic area : Indonesia and Asia Pacific Australia

- Value-creation : Product innovation, Brand, Technical expertise and Sustainability. 


\section{International Journal of Current Science Research and Review}

ISSN: 2581-8341

Volume 05 Issue 01 January 2022

DOI: 10.47191/ijesrr/V5-i1-29, Impact Factor: 5.825

IJCSRR@ 2022

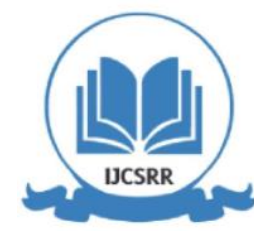

www.ijcsrr.org

To pursue growth, PTCI will need to expand the commodity chemical category in Textile and Consumer Care sector while upgrading for its facility and expertise to adopt higher complexity product portfolios in Consumer Care until it can handle NPP products from Consumer and Life Sciences sector. The products can be marketed domestically and within the Asia Pacific region. The core technology will be an emulsifier where PTCI expertise lies. The value is created through product innovation, sustainability initiative, and technical expertise to strengthen the PTCI parent company brand.

Vehicles is about decisions on how to get there. Specifically, the means for attaining the needed presence in a particular product category, market segment, geographic area, or value-creation stage. One of the tools that can used is build-borrow-or-buy framework from L. Capron and W. Mitchell (2012), Build, Borrow, or Buy: Solving the Growth Dilemma (Boston: Harvard Business Review Press). PTCI is able to learn how to select the right pathways to obtain new resources are more likely to gain and sustain a competitive advantage. NPP products and specialty chemical products are portfolios that need to be developed internally or built as the cost to borrow or buy is high. But in the case of strategic portfolio acquisition is a way to get the expertise and portfolio. On the other hand, commodity chemicals can have options for expansion. Internal development will have a longer time frame. For a faster time, options like contractual alliance can be developed to exploit PTCI brand and expertise with its partner strength in the economics of scale, low-cost manufacturing, etc.

PTCI differentiations are related to its product innovation to develop new patented products (NPP) that account for $28 \%$ revenue. Technical application expertise also brings value to bridge technical aspects between customer and their end consumer. Product quality and reliability is also one of PTCI differentiation with its customer that is synergies with the technical expertise to give brand excellence recognition.

In the case of PTCI, as in terms of complexity and quality standard, it is at the base of the standard. Thus, PTCI needs to expand the technical expertise through the product transfer process from Textile, Home Care and Crop Care sectors. Then, PTCI can enter the higher quality standard in the Personal Care sector. This sequence also will shift the share from the commodity portfolio to the specialty portfolio that can sustain growth better.

Economic Logic is a clear idea of how profits will be generated — not just some profits, but profits above the firm's cost of capital. PTCI revenue and growth will be sustained by NPPs and specialty chemicals portfolio as its core competencies. PTCI needs to shift from commodity to specialty portfolio then NPPs.

The strategy is applied in Home Care, Crop Care and Textile sectors Arenas. The Vehicles will be internal development through product transfer process. The Differentiator is the product innovation, technical expertise, and product transfer processes. The Staging is from start with strengthening the technical expertise and quality standard then expanding to a higher complexity portfolio. Economic Logic to sustain revenue and profit growth is through shifting commodity products to specialty products portfolio.

\section{RESULT AND DISCUSSION}

The different futures that result from the interaction of the critical, selected uncertainties are called scenarios. (Garvin \& Leverque, 2005) The scenarios are plausible, alternative postulates concerning how the world might unravel the future. It is specifically designed to highlight the risks and opportunities faced by organizations in each of the scenarios. The scenarios are constructed from a 2x 2 matrix of the critical uncertainties selected, economic growth and product innovation and the time frame is 5 years from 2021 to 2026 .

Economic growth is driving forces with high levels of uncertainty due to covid-19 pandemic. In 2020, Indonesia's economy contracted for the first time since the late 1990s Asian financial crisis. Even Indonesia's economic outlook has been adjusted in 2021 as the realization does not hit the projection. This uncertainty brings an undesirable outlook for the scenarios but also unfolds opportunities for sectors that can sustain or even bloom during the pandemic.

Product innovation also has a high level of uncertainty as the Indonesian market does not readily absorb certain technology portfolios. Advanced product acceptance is subject to the market and industry preference. Mature markets such as Personal Care and Home care normally use specialty chemicals over commodities as FMCG tend to use product differentiation to win the competition in developed countries. But in the case of the Indonesian market, it's not really applied. It depends on the segment as consumer preference may differ. Consumers tend to choose price over differentiation in certain markets and the opposite applies in different markets. This study $2 \times 2$ matrix is using stories about coffee. The scenario framework is shown in Figure 3. 


\section{International Journal of Current Science Research and Review}

ISSN: 2581-8341

Volume 05 Issue 01 January 2022

DOI: 10.47191/ijesrr/V5-i1-29, Impact Factor: 5.825

IJCSRR@ 2022

www.ijcsrr.org

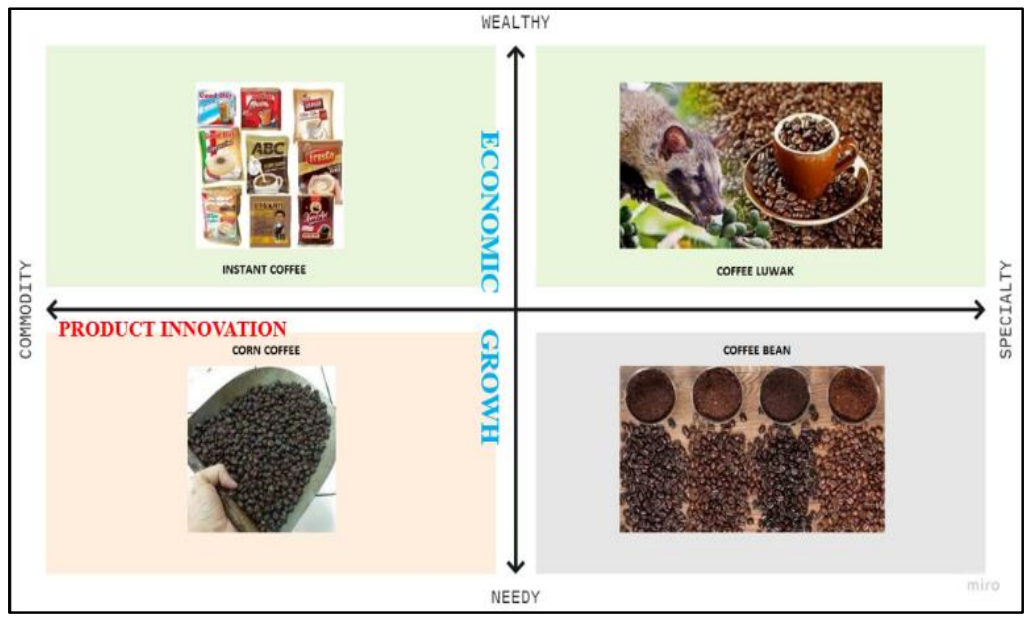

Figure 3. Scenario Matrix

Generation of implications and selection of options stage is when scenario planners start thinking about their own organization and the impact of the scenarios on their own strategic choices. One of the objectives is to identify implications and to look for gaps, vulnerabilities, opportunity, challenge, risk, that might occur in the future of each scenario. While options are a list of alternative strategies for "robustness" the ability to be successful over the full range of possible scenarios. This stage results in a list of strategies to implement and actions to consider, as well as a sense of the robustness of different approaches. (Garvin \& Leverque, 2005) This stage results in a list of strategies that can be implemented during the timeframe and actions needed to be considered, as well as a sense check to the robustness of different approaches.

Corn coffee (Low economic growth, Low product innovation)

During periods of depression and without product innovation, the sectors that can be the backbone to growth are commodities in all PTCI sectors that are essential or related to basic needs. Sectors such as Personal Care are limited to basic functions for hygiene but not beauty or wellness products. Home Care also will adopt commodities such as basic detergent over environmental-friendly ones.

Coffee bean (Low economic growth, High product innovation)

During periods of depression and product innovation still exist, the sectors that can be backbone to growth are still commodities in all PTCI sectors in the essential sectors. But there are opportunities for specialty chemicals in the essential sectors like health care and personal care that need to adopt better technology.

Instant coffee (High economic growth, Low product innovation)

When the economy is growing but technology adoption is still low due to inadequate knowledge people will still use commodities although they can afford to spend more. Thus, PTCI can focus both in the essential and non-essential sectors. Essential sector will be the majority source of revenue. Although, specialty product could bring more value to its customer, it will not get the market if it is not promoted, and the customers are educated with the product knowledge.

Luwak coffee (High economic growth, High product innovation)

Only when the economy is growing, and technology adoption is flourishing will people still use products with more value and genericity. Now they can afford to spend more and know about the value of the specialty product. PTCI can focus both in the essential and non-essential sectors. Essential sectors will be the majority source of revenue while non-essential sectors normally provide better profit. Specialty products that bring more value to its customer still need marketing effort to penetrate and educate the market as they have the money and also the idea. By then brand equity became important in the process.

Product innovation indicator depend on the trend in the population and related to the R\&D expenditure as innovative product will need investment in research and development. Investment in R\&D need strong technology infrastructure and increase human capital. Along with an increased in education, people will have tendency to adopt differentiated product. The Early Warning System for the plausible scenario are GDP growth, Price stability, GDP per capita, Exchange rate, Household consumption, Spending on nonessential, Market trend, R\&D expenditure. 


\section{International Journal of Current Science Research and Review}

ISSN: 2581-8341

Volume 05 Issue 01 January 2022

DOI: 10.47191/ijcsrr/V5-i1-29, Impact Factor: 5.825

\section{CONCLUSIONS}

Every business wants to maintain its existence and bring value to its stakeholders. Divestment and merger acquisition are part of the company strategy to achieve business growth that fulfil the company objectives, purpose, vision, and mission. In the case of a multinational company, it normally would have a global corporate strategy. Subsidiary companies will follow the strategic guidelines from its parent company. PTCI, as a subsidiary, also needs to align its strategy to the parent global corporate strategy. Scenario planning used to answer the key focal issue about how to align PTCI strategy to PTCI parent company global corporate strategy.

The identified driving forces that affect the business landscape are political, economic, socio-cultural, technology, and legal following the PESTEL framework. Ecological factors are excluded as driving forces as PTCI parent company has put a target on SDG. Thus, make this factor become mandatory aspect to be fulfilled not a trend that will shape up the future.

Two critical uncertainties are chosen with the highest preference in impact and uncertainty. Although there are different perspectives between the core team (country and regional leadership team) and the frontliners (operation and commercial team). This study picks driving forces with the highest score. Two critical uncertainties used are economic condition and product innovation acceptance that composed PTCI portfolio.

Utilizing the two critical uncertainties to prepare a $2 \times 2$ matrix, this study builds 4 plausible scenarios for the business landscape that need to be penetrated to achieve growth then survival. The scenarios are mentioned below:

1. Low Economic growth, Low Product Innovation

The conditions where both critical uncertainties are in the low condition and required PTCI to focus on product innovation for basic needs and essential product or services.

2. Low Economic growth, High Product Innovation

It is conditions where economic growth is low, but the market can adopt products with high levels of innovation. PTCI still needs to focus on product innovation for basic needs and essential products or services and penetrate the market that requires the innovative product.

3. High Economic growth, Low Product Innovation

The conditions were the opposite of the Coffee Bean scenario, where economic growth is high, but the market only adopts products with low levels of innovation. PTCI can expand its portfolio aside from basic needs and essential products or services to the non-essential such as beauty and wellness. PTCI needs to grab the market share as much as possible due to the economy is flourishing and the key for growth is from revenue rather than profit margin.

4. High Economic growth, High Product Innovation

During the high economic growth and the market adopt products and services that are highly innovative. PTCI needs to focus both to gain market share and penetrate the market that requires products that bring them value. Thus, PTCI can grow using a revenue stream with higher profit margin. Both in the basic and essential need with non-essential demand.

The early warning systems used as the leading indicators are GDP growth, Price stability, GDP per capita, Exchange rate, Household consumption, spending on non-essential, Market trend, R\&D expenditure.

\section{REFERENCES}

1. Baum, J. A., \& M.McGahan, A. (2004). Business Strategy over the Industry Lifecycle, Advances in Strategic Management, Vol. 21. Bingley, United Kingdom: Emerald).

2. Börjeson, L., Höjer, M., Dreborg, K.-H., Ekvall, T., \& Finnveden, G. (2006). Scenario types and techniques: Towards a user's guide. Futures (38) Issue 7, 723-739.

3. Deloitte. (2015). Capturing Indonesia Latent Market.

4. Garvin, D. A., \& Leverque, L. C. (2005, November). A Note on Scenario Planning. Harvard Business School Background Note 306-003.

5. Gelman, A., \& Park, D. K. (2008). Splitting a Predictor at the Upper Quarter or Third and the Lower Quarter or Third. The American Statistician Vol. 62, No. 4.

6. Goodwin, P., \& Wright, G. (2004). Decision Analysis for Management Judgment. West Sussex: John Wiley \& Sons.

7. Guattari, F., \& Deleuz, G. (1991). What is philosophy? New York: Columbia University Press. 


\section{International Journal of Current Science Research and Review}

ISSN: 2581-8341

Volume 05 Issue 01 January 2022

DOI: 10.47191/ijesrr/V5-i1-29, Impact Factor: 5.825

IJCSRR@ 2022

WWw.ijesrr.org

8. Guba, E., \& Lincoln, Y. (1994). Competing Paradigms in Qualitative Research. In Handbook of Qualitative Research (pp. 105-117). Thousands Oak: Sage.

9. Hambrick, D. C., \& Fredrickson, J. W. (2005). Are you sure you have a strategy? Academy of Management Executive.

10. Hax, A. C., \& Majluf, N. S. (1983). The use of the growth-share matrix matrix in strategic planning. Interfaces (13), 4660.

11. In-Cosmetics. (2020, June 29). Retrieved from https://connect.in-cosmetics.com: https://connect.in-cosmetics.com/regions/in-cosmetics-asia/gen-z-what-do-they-look-for-in-personal-care/

12. Jabareen, Y. (2009). Building a Conceptual Framework: Philosophy, Definitions, and Procedure. International Journal of Qualitative Methods, 8-12.

13. Lindgren, M., \& Bandhold, H. (2003). Scenario Planning - The link between future and strategy. New York: PALGRAVE MACMILLAN.

14. McKinsey\&Co. (2019, November 14). Five ways that ESG creates value. Retrieved from https://www.mckinsey.com/business-functions/strategy-and-corporate-finance/our-insights/five-ways-that-esg-createsvalue

15. Mohajan, H. K. (2018). An Analysis on BCG Growth Sharing Matrix. Noble International Journal of Business and Management Research.

16. Porter, M. E. (2008, January). The Five Competitive Forces That Shape Strategy. Harvard Business Review.

17. Rothaermel, F. T. (2021). Strategic Management: Concepts \& Cases. New York: McGraw-Hill.

18. Washington State Universities Libraries. (2021). Retrieved from WSU Libraries: https://libguides.libraries.wsu.edu/c.php?g=294263\&p=4358409

19. Wiek, A., Binder, C., \& Scholz, R. W. (2006). Functions of scenarios in transition processes. Futures (38), 740-766.

20. Wikipedia. (2021, October). Retrieved from https://en.wikipedia.org: https://en.wikipedia.org/wiki/Environmental,_social_and_corporate_governance

21. World Bank. (2014). Indonesia Development Policy Review.

22. World Bank. (2019). Aspiring Indonesia - Expanding the Middle Class.

Cite this Article: Welliam, Pri Hermawan (2022). Aligning PTCI Strategies to Global Corporate Strategies Using Scenario Planning. International Journal of Current Science Research and Review, 5(1), 248-255 